\title{
Improved processing method of UEGN-2002 gravity network measurements in Hungary
}

\author{
L. Völgyesi, L. Földváry \\ Department of Geodesy and Surveying, Budapest University of Technology and Economics; Research Group \\ of Physical Geodesy and Geodynamics of the Hungarian Academy of Sciences, H-1521 Budapest, Hungary. \\ G. Csapó \\ Eötvös Loránd Geophysical Institute of Hungary, H-1145 Budapest, Hungary, Kolumbusz u. 17-23.
}

\begin{abstract}
A new method and software has been made and tested in the Hungarian part of the UEGN-2002 network. Making a suitable base gravity network and providing proper data for UEGN2002 has required some experimental measurements and many important investigations. In case of precise gravity measurements the determination of the vertical gradient's real value is necessary. Using the real or normal value of vertical gradients may give 6-10 $\mu \mathrm{Gal}$ differences of height reductions depending on the reference height of the instruments. Taking into account the periodical errors of LCR gravimeter's reading device is very important; neglecting the periodical errors may give $25-30 \mu \mathrm{Gal}$ errors of $\Delta g$ between measured points depending on the instrument (in case of our instruments LCR 963 and 1919 it was found to be below $2 \mu \mathrm{Gal}$ ). We have found that the accuracy of the parameter estimation increases with fewer periods estimated. We suggest to always using a full parameter set for the estimation of the periodical correction. Based on our investigations the reliability of the MGH-2000's adjusted data is significantly better, than the reliability of the European network's one (probably because of the different reliabilities of the different European countries' gravity data). According to our plans, after the final adjustment of UEGN-2002 we are going to readjust the Hungarian MGH-2000 taking into account the adjusted $g$ values of UEGN-2002.
\end{abstract}

Keywords. Gravimeters, gravity measurements, gravity networks, vertical gradient, periodical errors, corrections of measurements, adjustment

\section{Introduction}

The International Union of Geodesy and Geophysics (IUGG) has long been planning to set up a unified scale and datum gravimetric network which could be applicable in the whole continent of Europe. Its conditions have been established when several countries have got absolute gravimeters, providing unified scale in accordance with the current accuracy specifications. At the same time the need for increasing the accuracy of global geodetic reference systems, and for solving several geodynamic and geotectonic problems, have brought about the realisation of this objective as a daily routine. Among others this purpose was served by the establishment of Unified European Gravity Net (UEGN-93) by 11 countries (Boedecker, 1993). Later further countries such as Hungary have been joined to UEGN and completed some necessary works (making new absolute points and performing common measurements on the neighbouring countries' network) for the joining. Unfortunately significant inhomogeneities of the UEGN-93 point distribution can be seen, investigating the networks of the different UEGN countries. As far as we know there is no country which has transformed its own network to the UEGN datum up to now. However this is an important problem and according to our plans after the final adjustment of UEGN-2002 we are going to readjust the Hungarian MGH-2000 taking into account the adjusted $g$ values of UEGN2002 referring to Hungary as constraints of a fixed network.

\section{The former Hungarian gravity net- works}

We provide an overview of processing and adjustment methods that have been applied for the gravimetric network in Hungary from the beginning of the fifties up to now. In former times to make use of complex equations was not feasible according to the computational capacity of the time, so many factors have been neglected, e.g. instrument drift.

For the first time, the Hungarian gravimetry network has been determined in the 1950s (referred as MGH-50). Both the processing and the adjustment have been done manually; solving this problem was a definitely time consuming procedure. In the eighties due to the development of computers, processing of data with much larger set of unknowns be- 
came executable. The registration of the observations, the processing method and also the adjustment became much more easily feasible, providing more space for optimization of the solution, e.g. the parameterisation of the processing sequence could be done in different manners (a priori and a posteriori as well), or tests could be performed for an optimal adjustment method.

Previously the memory limits of computers allowed solving for some hundred unknowns in a short duration. Nevertheless, in order to be able to handle more unknowns in a more flexible way and to consider more effects than before (e.g. changes in water table, periodical errors of the data registration), the development of an up-to-date software became necessary. A new method and software has been made and tested in the Hungarian part of the UEGN-2002 network and the accuracy of the adjusted gravity network has been improved.

Hungary's first gravity network (MGH-50) covering the entire territory of the country was established by the Loránd Eötvös Geophysical Institute (ELGI) during the early 1950s. The measurements were carried out by a Heiland GSC-3 astatic gravimeter. Both the processing and the adjustment of these measurements have been carried out manually in 1954. This network was containing 16 first order and 493 second order points. Description of measurements, processing's and adjustment's method and the results can be found in (Renner and Szilárd 1959). Constraints of the second order network adjustment were the adjusted $g$ values of the first order network points. MGH-50 gravity network was adjusted in the Potsdam Gravity System. It is interesting to mention that a correction of magnetic azimuth was applied here for the first time; this type of correction was applied nowhere else before. At the same time the height correction was not applied here. According to our estimations considering that all measurements were made on a special tripod, omitting the height corrections may cause about 5$15 \mu \mathrm{Gal}$ errors of adjusted $g$ values.

As a result of industrial and infrastructural developments during the 1960-70s, most of the base points established mainly along national roads were beginning to deteriorate or simply became unsuitable for their original purposes. This was the main reason why a new gravity network had been established during the 1980-88s. One part of network measurements was performed in international cooperation (Csapó et al, 1994), and 8 Sharpe, 4 Worden and 1 LCR-G gravimeters were applied in the measurements. Before the adjustment process a lot of different investigations were performed (Csapó, Sárhidai 1990a) and the results were applied to our newest gravity network. The network has been adjusted as a fixed one by LSQ method, this was the common adjustment of the first and the second order network. The constraints were the $g$ values of the 5 absolute points measured by the GABL absolute gravimeter. A lot of different adjustment version was investigated, but each version of adjustment used the measured $\Delta g$ values between points as an independent measurement data (Csapó, Sárhidai 1990b). The error of unit weight of the adjusted network is $\mu_{0}= \pm 16 \mu \mathrm{Gal}$, the errors of adjusted values are $\pm 2-9 \mu \mathrm{Gal}$ for the 408 points $(1 \mu \mathrm{Gal}=$ $10^{-8} \mathrm{~ms}^{-2}$ ).

\section{Necessity of determination of a new Hungarian gravity network}

The establishment of the newest gravity network MGH-2000 in Hungary and the necessity of a new processing of the measurements are essential due to several reasons (Csapó, Völgyesi, 2001). First of all, several new absolute measurements have been performed in the country. Moreover the points of Hungarian part of UEGN-2002 are taken out from the points of the new MGH-2000 network demanding an increased need in accuracy.

Making a suitable base gravity network and providing proper data for UEGN-2002 has required some experimental measurements and many important investigations. In what follows these investigations and results are presented.

\section{Influence of local vertical gradients on the values of $\Delta g$ between points}

Generally only the normal value of vertical gradient $(0.3086 \mathrm{mGal} / \mathrm{m})$ is used for height reduction of gravity measurements instead of the real value. During last years we have determined the real value of vertical gradients at different points and found a difference $20-25 \%$ between the real and the normal values (Csapó, Völgyesi, 2004). In Table 1 values of measured vertical gradients can be seen as examples in some points in Hungary. In this table $\varphi$ and $\lambda$ denote ellipsoidal coordinates, $H$ is the height of the point and $V G$ is the vertical gradient.

In case of precise gravity measurements (e.g. measurements on a calibration base line or measurements on special polygons for investigations of local variations of gravity) the use of observed vertical gradient's real value is necessary. Using the observed or normal value of vertical gradients may give $6-10 \mu \mathrm{Gal}$ differences of height reductions depending on the reference height of an instrument 
above the benchmark (e.g. the reference height of LCR gravimeters are about $50-250 \mathrm{~mm}$ ). So it is obvious that instrument height should be chosen as small as it is possible and should be the same at different points.

Table 1. Measured vertical gradient $(V G)$ values in Hungary in $\mu \mathrm{Gal} / \mathrm{m}\left(1 \mu \mathrm{Gal}=10^{-8} \mathrm{~ms}^{-2}\right)$

\begin{tabular}{|l|c|c|r|c|}
\hline \multicolumn{1}{|c|}{ Point } & $\varphi$ & $\lambda$ & \multicolumn{1}{c|}{$H$} & $V G$ \\
\hline \hline 106 /Ercsi/ & $47-14-58$ & $18-53-57$ & 124 & -309.3 \\
\hline 92.0/Madocsa/ & $46-41-19$ & $18-57-40$ & 94 & -255.2 \\
\hline 2142 /Táborhegy/ & $47-33-01$ & $19-00-31$ & 412 & -354.7 \\
\hline 82 /Budapest UEGN/ & $47-32-00$ & $19-01-00$ & 202 & -251.9 \\
\hline 821 /Mátyáshegy/ & $47-32-00$ & $19-00-57$ & 201 & -262.5 \\
\hline 103 /Tolna/ & $46-25-20$ & $18-47-32$ & 100 & -310.7 \\
\hline 2143 /Hármashatárh./ & $47-33-23$ & $19-00-10$ & 463 & -386.0 \\
\hline 107 /Budaörs/ & $47-26-58$ & $18-59-14$ & 126 & -308.2 \\
\hline
\end{tabular}

\section{Investigation of periodical errors of LCR gravimeter's reading device}

Periodical errors of LCR gravimeter's reading device are discussed in many publications, e.g. Becker (1984), Lederer (2004). Neglecting the periodical errors can give 25-30 $\mu \mathrm{Gal}$ errors of $\Delta g$ between measured points. Determination of periodical errors is possible by measurements in special calibration lines or in laboratories (Chao, Baker 1984).

Lederer (2004) has determined the periodical errors of several LaCoste gravimeters, including our two instruments LCR 963 and LCR 1919. His analysis is based on observations at two gravimetric baselines in Pecny-Chocerady (Czech) and in Modra-Piesok (Slovakia) in 2002.

The range of these calibration lines is about 40 mGal. The Pecny-Chocerady baseline contains 16 points, the intervals varies between $0.2 \div 16.2$ mGal. The Modra-Piesok baseline contains 31 points with uniform intervals of about $4 \mathrm{mGal}$.

After the adjustment of UEGN-2002 we are planning to re-process and re-adjust the measurements of MGH-2000, therefore taking into account the periodical errors of gravimeters is important in our new software. So the analysis has been reperformed for LCR 963 and LCR 1919 gravimeters based on the earlier observations in the calibration line of Pecný-Chocerady. The reason of the reanalysis is that the classical sine-cosine and the spectral representations of the Fourier series used in Lederer (2004) were found to be inconsistent. Probably the phase has been provided incorrectly.

The periodical error was defined as a discrete Fourier-series, with the discrete periods being related to the radius of the gears inside the instrument.
The range of the observations with LCR 963 varies between 4378 and $4425 \mathrm{mGal}$, and with LCR 1919 between 4439 and $4482 \mathrm{mGal}$, therefore no longer periods of the instruments could be determined. Periods which can be determined are 1.00, 3.67, 7.33 and $36.67 \mathrm{mGal}$ (or equivalently CU - counter unit) in case of LCR 963, and 1.00, 3.94, 7.88 and $35.47 \mathrm{mGal}$ (CU) in case of LCR 1919. The equation of the periodical errors is

$$
\begin{aligned}
x\left(t_{i}\right)=A_{0}+\sum_{k=1}^{K}\left(C_{k}\right. & \cos \left[\frac{2 \pi}{P_{k}}\left(t_{i}-T_{0}\right)\right] \\
+ & \left.S_{k} \sin \left[\frac{2 \pi}{P_{k}}\right]\left(t_{i}-T_{0}\right)\right)
\end{aligned}
$$

where $t_{i}$ is a dial reading, $x$ is the variation of gravity after the adjustment, $A_{0}$ is the bias of the observations, $P$ is the periods, $K$ is the number of the periods, $C$ and $S$ are the Fourier coefficients, $T_{0}$ is a phase shift, which can be chosen arbitrarily. In spectral representation, it reads

$$
x\left(t_{i}\right)=A_{0}+\sum_{k=1}^{K}\left(A_{k} \sin \left[\frac{2 \pi}{P_{k}}\left(t_{i}-T_{0}\right)+\varphi_{i}\right]\right),
$$

where $A_{i}=\sqrt{C_{i}^{2}+S_{i}^{2}}$ and $\varphi_{i}=\arctan \left(C_{i} / S_{i}\right)$.

Parameters of the periodical errors have been determined considering 4 different periods $(1.00,3.67$, 7.33 and 36.67 CU for LCR 963, and 1.00, 3.94, 7.88 and 35.47 CU for LCR 1919). The results are shown in Table 2 and 3 for LCR 963 and Table 4 and 5 for LCR 1919. Dimensions of $P$ and $T_{0}$ are CU (Counter Unit), that of $\varphi$ is decimal degree, and all the other quantities are in $\mu \mathrm{Gal}$.

Comparing the parameters to Lederer (2004), significant differences can be detected. Unfortunately no certain information of Lederer's adjustment is available. However, there are still some known differences of the parameterisation, e.g. Lederer has chosen $T_{0}$ below the minimum of the observations, $t$, while in our case it was chosen to be the mean of them. Due to the difference in choice of $T_{0}$, comparison only in the non-phaserelated variables can be sought for, e.g. $A$ or $A_{0}$ but not in $C, S$ and $\varphi$.

The a posteriori standard deviations in these tables are denoted by $m$, and are in the same order as the signals themselves. Comparing the parameters in Table 2 with Table 3, and Table 4 with Table 5, it can be seen that the accuracy of the parameter estimation increases with less periods estimated. In general, it is clear that the parameters vary notably by the choice of the estimated periods. We have investigated how large variations of the amplitude 
can be found due to the choice of the periods. All possible combinations of these 4 periods have been adjusted; it provided 8 estimations for every period. The accuracy estimate of the amplitudes is provided in Table 6.

Table 2. Estimated parameters of periodical correction for LCR 963 considering 4 periods.

\begin{tabular}{|c|c|c|c|c|c|r|}
\hline$P$ & $T_{0}$ & $A_{0}$ & $m A_{0}$ & $A$ & $m A$ & $\varphi$ \\
\hline 1.00 & 4401.5625 & 23.15 & 1.25 & 1.47 & 1.44 & 142.98 \\
\hline 3.67 & 4401.5625 & 23.15 & 1.25 & 0.65 & 1.74 & 86.75 \\
\hline 7.33 & 4401.5625 & 23.15 & 1.25 & 1.97 & 1.84 & 7.06 \\
\hline 36.67 & 4401.5625 & 23.15 & 1.25 & 0.96 & 2.30 & 102.61 \\
\hline
\end{tabular}

Table 3. Estimated parameters of periodical correction for LCR 963 considering 3 periods.

\begin{tabular}{|c|c|c|c|c|c|c|}
\hline$P$ & $T_{0}$ & $A_{0}$ & $m A_{0}$ & $A$ & $m A$ & $\varphi$ \\
\hline 1.00 & 4401.5625 & 22.58 & 0.72 & 1.48 & 1.32 & 137.40 \\
\hline 3.67 & 4401.5625 & 22.58 & 0.72 & 0.53 & 1.41 & 54.30 \\
\hline 7.33 & 4401.5625 & 22.58 & 0.72 & 1.61 & 1.67 & 3.46 \\
\hline
\end{tabular}

Table 4. Estimated parameters of periodical correction for LCR 1919 considering 4 periods.

\begin{tabular}{|c|c|c|c|c|c|c|}
\hline$P$ & $T_{0}$ & $A_{0}$ & $m A_{0}$ & $A$ & $m A$ & $\varphi$ \\
\hline 1.00 & 4466.0160 & -5.52 & 0.47 & 0.74 & 0.54 & 259.95 \\
\hline 3.94 & 4466.0160 & -5.52 & 0.47 & 0.35 & 0.60 & 224.31 \\
\hline 7.88 & 4466.0160 & -5.52 & 0.47 & 0.18 & 0.62 & 317.99 \\
\hline 35.47 & 4466.0160 & -5.52 & 0.47 & 0.31 & 0.67 & 136.28 \\
\hline
\end{tabular}

Table 5. Estimated parameters of periodical correction for LCR 1919 considering 3 periods.

\begin{tabular}{|c|c|c|c|c|c|c|}
\hline$P$ & $T_{0}$ & $A_{0}$ & $m A_{0}$ & $A$ & $m A$ & $\varphi$ \\
\hline 1.00 & 4466.0160 & -5.68 & 0.28 & 0.81 & 0.50 & 257.61 \\
\hline 3.94 & 4466.0160 & -5.68 & 0.28 & 0.43 & 0.56 & 218.99 \\
\hline 7.88 & 4466.0160 & -5.68 & 0.28 & 0.07 & 0.58 & 295.74 \\
\hline
\end{tabular}

Table 6. Accuracy estimate of the amplitude $A$ due to the choice of the periods.

\begin{tabular}{|l|c|l|c|}
\hline \multicolumn{2}{|c|}{ LCR 963} & \multicolumn{2}{c|}{ LCR 1919} \\
\hline$P[C U]$ & $A[\mu \mathrm{Gal}]$ & $P[C U]$ & $A[\mu \mathrm{Gal}]$ \\
\hline 1.00 & $1.43+/-0.05$ & 1.00 & $0.78+/-0.05$ \\
\hline 3.67 & $0.90+/-0.33$ & 3.94 & $0.43+/-0.08$ \\
\hline 7.33 & $1.79+/-0.23$ & 7.88 & $0.48+/-0.32$ \\
\hline 36.67 & $0.71+/-0.37$ & 35.47 & $0.35+/-0.09$ \\
\hline
\end{tabular}

The statistics show that no relevant differences at period 1.00 CU can be found, but the others can differ notably. According to the results, we suggest to always use a full parameter set for estimation of the periodical correction.

\section{Corrections of gravity measurements}

According to our investigations the gravity difference $\Delta g_{A B}$ between points $\mathrm{A}$ and $\mathrm{B}$ can be expressed by the formula

$$
\begin{aligned}
& \Delta g_{A B}=M\left[\left(c_{B} \ell_{B}-c_{A} \ell_{A}\right)\right. \\
& \left.\quad+\delta g_{H}+\delta g_{p}+\delta g_{\text {tide }}+\delta g_{s k}+\delta g_{\text {drift }}\right]
\end{aligned}
$$

where $M$ is the scale factor of a gravimeter referring to the actual year determined on the national calibration line, $c_{A}$ and $c_{B}$ are the mean calibration factor or the value of the scale function referring to the scale readings $\ell_{A}$ and $\ell_{B}, \delta g_{H}$ is the height reduction, $\delta g_{p}$ is the barometric reduction, $\delta g_{\text {tide }}$ is the tidal correction, $\delta g_{s k}$ is the correction of periodical errors, and $\delta g_{d r i f t}$ is the drift correction.

Height reduction $\delta g_{H}$ can be computed as the product of the reference height of the gravimeter's sensing mass and the vertical gradient, so $\mathrm{mm}$ accuracy of reference height is necessary.

In case of computation of barometric reduction $\delta g_{p}$ taking into account of DIN standard No. 5450 is necessary:

$$
p_{n}=1013.25 \exp .\left(1013.25 \times 10^{-6} H\right) \text { mbar }
$$

so the barometric reduction:

$$
\delta g_{p}=\left(p-p_{n}\right) r .
$$

According to experiences of Boedecker and Richter (1984) to a similar climate we use the same empirical value of $r$ they employed, $r=0.3 \mu \mathrm{Gal} / \mathrm{mbar}$.

Tidal correction $\delta g_{\text {tide }}$ can be computed by

$$
\delta g_{\text {tide }}=\sum_{i} \delta_{i} A_{i} \cos \left(\varphi_{i}+\omega_{i} t+\kappa_{i}\right),
$$

where $i$ is the index of tidal wave, $A$ is the theoretical amplitude, $\varphi$ is the theoretical phase, $\omega$ is the angular velocity, $\delta$ is the deformation coefficient, $\kappa$ is the phase delay and $t$ is the universal time (UT). Altogether 237 different tidal waves have been considered in our computations. A value of the deformation coefficient $\delta=1.16$ have been used (Lassovszky, 1956). This procedure of tidal computation has been chosen because a lot of partners in our former international cooperation were using this type of computation too (Holub, 1988).

Drift correction $\delta g_{\text {drift }}$ is computed by the socalled slope method (Csapó, Sárhidai 1990a). 


\section{Adjustment of gravity network MGH- 2000}

The MGH-2000 network consists of 22 absolute points ( 7 points can be found in the neighbouring countries from these) and 442 further base points as it can be seen on Fig. 1. 5544 connections were measured by six LCR-G gravimeters between these points, partly in international cooperation. The accuracy of absolute points varies between $2 \div 4$ $\mu \mathrm{Gal}$. Two types of adjustment of these measurements have been performed, as a fixed network (i.e. the absolute points are fixed) and as a free network (i.e. values of absolute points can change during the adjustment).

First the MGH-2000 network has been adjusted as a fixed network by Least Squares method. The constraints of the network were the $g$ values of the 22 absolute points.

Performing the adjustment the Danish iteration procedure was applied. To decrease the effect of relatively large errors in the adjustment the weights of measured data having been greater errors should be decreased, but before the adjustment the errors are not known. This contradiction can be solved by iteration. In the first step $(j=1)$ all observed data has equal weight $\left(p_{i 1}=1\right)$. In the further steps the weight of the $i^{\text {th }}$ measurement will be:

$$
p_{i j}=\frac{1}{1+a_{k} v_{j-1}^{2}}
$$

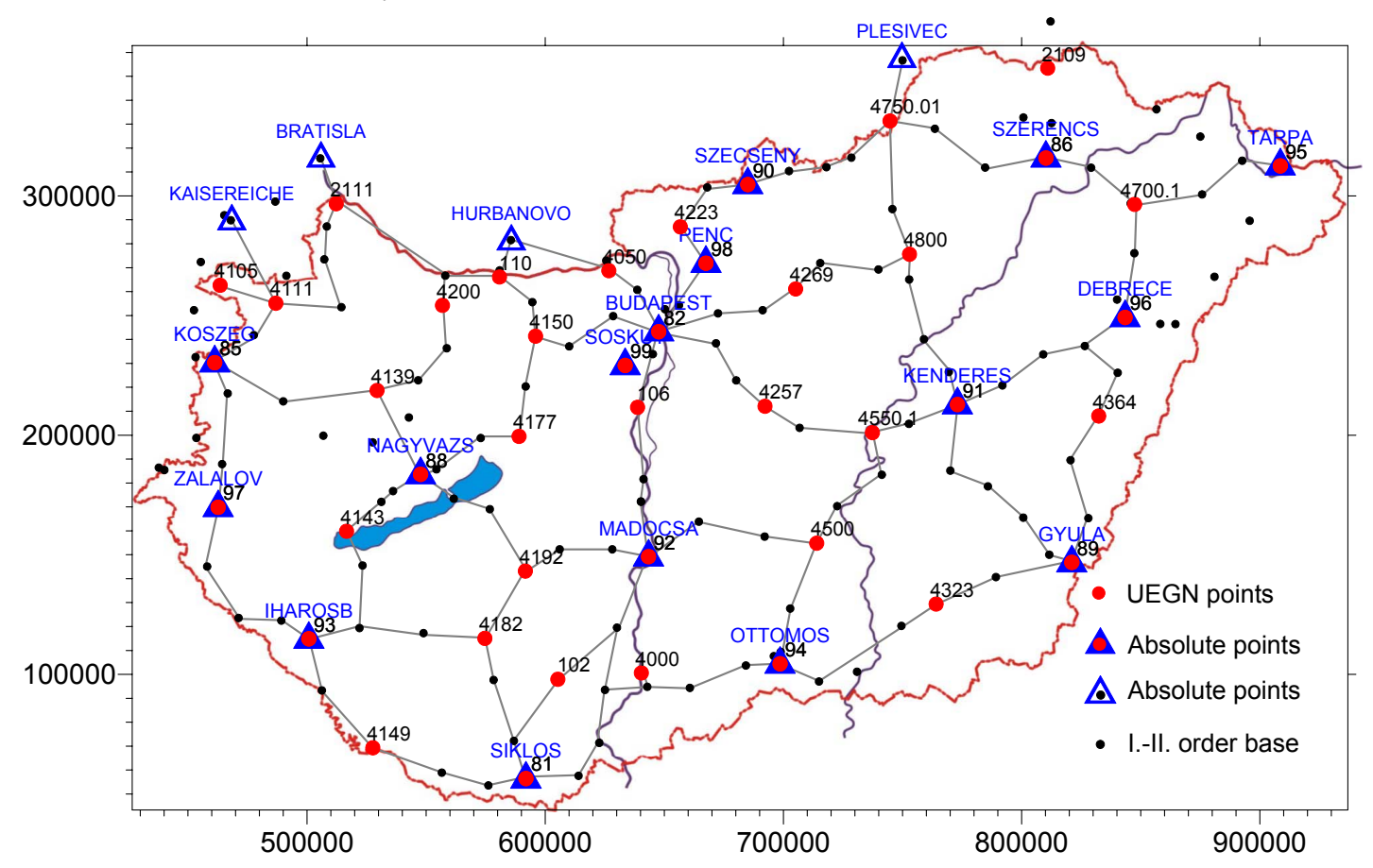

Fig. 1. The structure of MGH-2000 where $j$ is the actual iteration step and $v_{j-1}$ is the residual from the previous step. The coefficient $a_{k}$ is appropriate when $p=0.25$ for the erroneous measurement (Soha, 1986). The threshold of errors can be taken as the function of the errors of unit weight, then:

$$
a_{k}=3 / v_{k}^{2}
$$

where

$$
\begin{array}{lll}
v_{k}=3 \mu_{0} & \text { if } & v_{\max }>3 \mu_{0} \\
v_{k}=2 \mu_{0} & \text { if } & 2 \mu_{0}<v_{\max }<3 \mu_{0} \\
v_{k}=\mu_{0} & \text { if } & \mu_{0}<v_{\max }<2 \mu_{0} .
\end{array}
$$

The erroneous measurements will get less weight by each subsequent iteration step. The iteration should be repeated until the error of unit weight is decreasing in a considerable way. In the adjustment of MGH-2000 three steps of iteration proved to be sufficient. The error of unit weight of the adjusted network is $\pm 14 \mu \mathrm{Gal}$, the average error of the adjusted values is $\pm 7 \mu \mathrm{Gal}$.

In the second case the MGH-2000 network has been adjusted as a free network. In this case the $g$ value of Budapest absolute station has been used for reference level.

Differences of adjusted $g$ values are about \pm 20 $\mu \mathrm{Gal}$ coming from the two types of adjustment. 


\section{Comparison the results of different adjustment's data}

After the simultaneous adjustment of the Hungarian, Czech and Slovakian gravity network, comparison of the three adjusted results was possible. Each country considered the common gravity points and the partner's measurements for their own adjustment. The Czech and Slovakian adjustment have been performed as a free network's adjustment (Charamza, Träger 1971).

We compared our adjusted values to the Czech and Slovakian results on those points which were included in the adjustment all of three networks. The maximum deviation we have obtained on identical points was about 3-8 $\mu \mathrm{Gal}$. The results can be regarded as excellent taken into consideration the differences of the three networks (different gravimeters, database, and adjustment). Similarly, two further comparisons were made. We compared the Hungarian, Austrian and UEGN'94 gravity datum (Csapó et all, 1993) based on 8 common points (i.e. points which are included in both networks). The Hungarian datum proved to be higher than the Austrian by $18 \mu \mathrm{Gal}$. We compared the gravity values obtained for common points in the adjustment of UEGN '94 and MGH-2000. We could do this because five Hungarian points which were part of the Austrian-Hungarian interconnecting measurements in 1992-93 were already included in the adjustment of UEGN '94. Based on the five points the Hungarian datum is higher by $14 \mu \mathrm{Gal}$ than the UEGN '94 one (see Table 7).

Table 7. Comparison of UEGN ' 94 and MGH-2000 data

\begin{tabular}{|l|c|c|c|}
\hline \multicolumn{1}{|c|}{ Point } & \multicolumn{2}{|c|}{ Gravity [mGal] } & Diff. \\
\hline & UEGN'94 & MGH-2000 & {$[\mu \mathrm{Gal}]$} \\
\hline \hline Fertöd & $980824,222 \pm 8,0$ & $980824,234 \pm 4,9$ & 12 \\
Hegyesh. & $980844,449 \pm 12,0$ & $980844,460 \pm 7,0$ & 11 \\
Köszeg & $980784,705 \pm 15,0$ & $980784,713 \pm 5,0$ & 8 \\
Sopron & $980808,350 \pm 14,0$ & $980808,375 \pm 5,4$ & 25 \\
Völcsej & $980802,189 \pm 14,0$ & $980802,203 \pm 4,1$ & 14 \\
\hline
\end{tabular}

It can be seen from Table 7 that the reliability of the MGH-2000's adjusted data is significantly better than the reliability of European network's one (because of the different reliabilities of the different European countries' gravity data).

According to our plans after the final adjustment of UEGN-2002 we are going to readjust the Hungarian MGH-2000 taking into account the adjusted $g$ values of UEGN-2002 referring to Hungary as constraints of a fixed network.

\section{Acknowledgements}

Our investigations are supported by the National Scientific Research Fund OTKA T-037929.

\section{References}

Becker M (1984): Analyse von hochpräzisen Schweremessungen. DGK, Reihe C, Nr 294 (Dissertationen), pp. 37-50. München.

Boedecker G, Richter B (1984): Das Schweregrundnetz 1976 der Bundesrepublik Deutschland. Teil II. DGK, Reihe B, $\mathrm{Nr}$ 271, pp. 30-31. München.

Boedecker G (1993): Ein einheitliches Schweregrundnetz für Europa. Zeits.f.Verm.wesen 8/9, pp. 422-428.

Chao D, Baker E M (1985): A study of the optimization problem for calibrating a LaCoste and Romberg „G” gravity meter to determine circular errors. OSU, Dep. of Geod. Sci. and Surveying, 1985. No 364, Columbus.

Charamza F, Träger L (1971): Bearbeitung der Messungsergebnisse auf den Schwerepolygonen. Geofysikalní Sbornik. XIX, pp. 109-119. Praha.

Csapó G, Sárhidai A (1990a): The new gravity basic network. Geod. és Kart. 42, 2, pp.181-190. (In Hungarian)

Csapó G, Sárhidai A (1990b): The adjustment of the new Hungarian gravimetric network (MGH-80). Geodézia és Kartográfia, 42, 3, pp.181-190. (In Hungarian)

Csapó G, Maurers B, Ruess D, Szatmári G (1993): Interconnecting gravity measurements between the Austrian and the Hungarian network. Geoph.Trans. 38, 4, pp. 251-259.

CsapóG, Szatmári G, Klobusiak M, Kovacik J, Olejnik S. Trage L (1994): Unified Gravity Network of the Czech Republic, Slovakia and Hungary. Springer, IAG Symposia, 113, pp.72-81

Csapó G, Völgyesi L (2001): Hungary's New Gravity Base Net (MGH-2000) and It's Connection to the UEGN. (IAG Symposia Vol.125) Springer, pp.72-77.

Csapó G, Völgyesi L (2004): New measurements for the determination of local vertical gradients. Reports on Geodesy, No.2 (69), pp. 303-308, Warsaw

Holub J (1988): Tidal Observations with Gravity Meter Gs15 at Station Pecný. Travaux Geoph., XXXIV, 4. Praha

Lassovszky K (1956): Determination of the Earth's deformation parameter from gravity measurements. Geodézia és Kartográfia, V., 1., pp.: 18-26. (In Hungarian)

Lederer M (2004): Periodical errors of gravimeters LaCoste \& Romberg. Land Survey Office, Dep. of Gravimetry, Prague. (Report)

Renner J, Szilárd J (1959): Gravity Network of Hungary. Acta Techn. Academiae Scientarum Hungaricae, XXIII., 4, pp. 365-395.

Soha G (1986): A robust adjustment with weights depending from measurement corrections. Geodézia és Kartográfia, 38, 4, pp. 267-271. (In Hungarian) 
Völgyesi L, Földváry L, Csapó G (2007) New processing of gravity network measurements in Hungary. Dynamic Planet 2005, Cairns, Australia. Tregoning P, Rizos C (Eds.) Springer-Verlag Berlin Heidelberg; Series: IAG Symposia, Vol. 130. pp. 202-207.

Dr. Lajos VÖLGYESI, Department of Geodesy and Surveying, Budapest University of Technology and Economics, H-1521 Budapest, Hungary, Müegyetem rkp. 3.

Web: http://sci.fgt.bme.hu/volgyesi E-mail: volgyesi@eik.bme.hu 